DOI: http://dx.doi.org/10.18203/2320-1770.ijrcog20162142

Case Report

\title{
An unusual case of constriction ring dystocia
}

\section{Balgopal Singh Bhati*, Arti Patidar, Archana Kori, Indra Bhati}

Department of Obstetrics and Gynaecology, S.N. Medical College, Jodhpur, Rajasthan, India

Received: 26 April 2016

Revised: 03 June 2016

Accepted: 04 June 2016

\section{*Correspondence:}

Dr. Balgopal Singh Bhati,

E-mail: drbsbhati@gmail.com

Copyright: (C) the author(s), publisher and licensee Medip Academy. This is an open-access article distributed under the terms of the Creative Commons Attribution Non-Commercial License, which permits unrestricted non-commercial use, distribution, and reproduction in any medium, provided the original work is properly cited.

\section{ABSTRACT}

We present here an unusual case of constriction ring dystocia. In the case during intra-partum abdominal contour look like Bandl's retraction ring but on cesarean section identified the constriction ring of uterine myometrium strangling the fetal forehead and face.

Keywords: Constriction ring, Dystcia, Bandl's retraction ring

\section{INTRODUCTION}

Obstructed labour or labour dystocia is a common emergency in obstetrics; but dystocia due to uterine ring is a rare phenomenon. A constriction ring has been reported to be a localized tetany of the uterus that occurs in prolonged labour with rupture of membranes. ${ }^{1}$ It is usually localized to a thickened area of the myometrium over a point of fetal body or at a level just below it. ${ }^{1-3}$ Therefore, it is differentiated from the Bandl's ring (pathological retraction ring) which is the abnormal junction between the two segments of uterus and also associated with the dysfunctional and prolonged labour. ${ }^{1,4,5}$ We present here a unusual case of constriction ring dystocia which on inspection looks like Bandl's rings due to abnormal abdominal contour (Figure 1 and 2).

\section{CASE REPORT}

A 22 year old primipara at 39 weeks of gestation was admitted at our hospital Dr. SN Medical College Jodhpur, Rajasthan, India in labour following rupture of the membranes. When she was admitted, she was in active labour with regular contraction of uterus occurring every 2-3 minutes. Examination revealed an unusual abdominal contour (Figure 1 and 2) along with $4 \mathrm{~cm}$ cervical dilatation with $80 \%$ effacement and fetal head was at higher station (-4 to -5$)$. Dystocia due to constriction ring or Bandl's ring was suspected. Fetal heart auscultation demonstrated an irregular pattern so NST done and Ultrasonography call was sent. NST was non-reactive so she was selected for a caesarean section. On opening of abdominal cavity, there were lower uterine segment was thickened and contraction ring of the uterine myometrium strangling the fetal head and face (Figure 3 and 4).

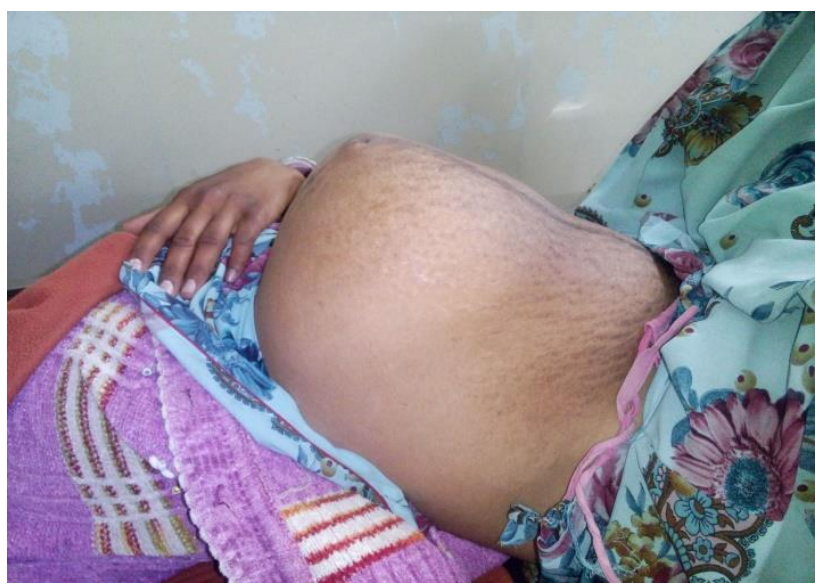

Figure 1: Abnormal contour of abdomen looks like Bandl's rings. 
A full term male infant of $3 \mathrm{~kg}$ with APGAR 8/9 was delivered. A mark of contraction ring was present on fetal head (Figure 5). After the deliveries of the fetus and placenta, the constriction ring disappeared (Figure 6). There was no intrauterine synechia or septum. Her puerperium was uncomplicated.

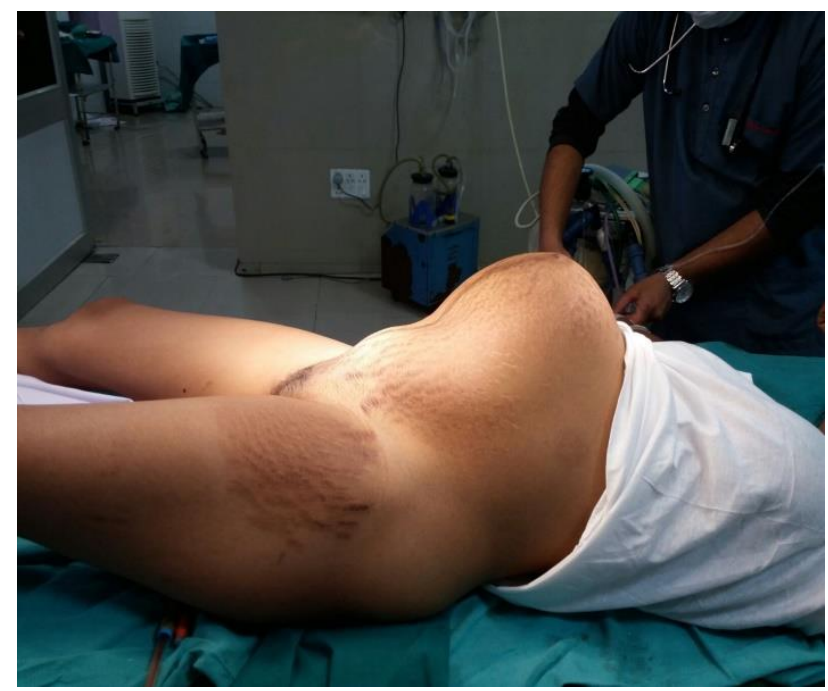

Figure 2: On antepartum on inspection looks like Bandl's rings due to abnormal abdominal contour.

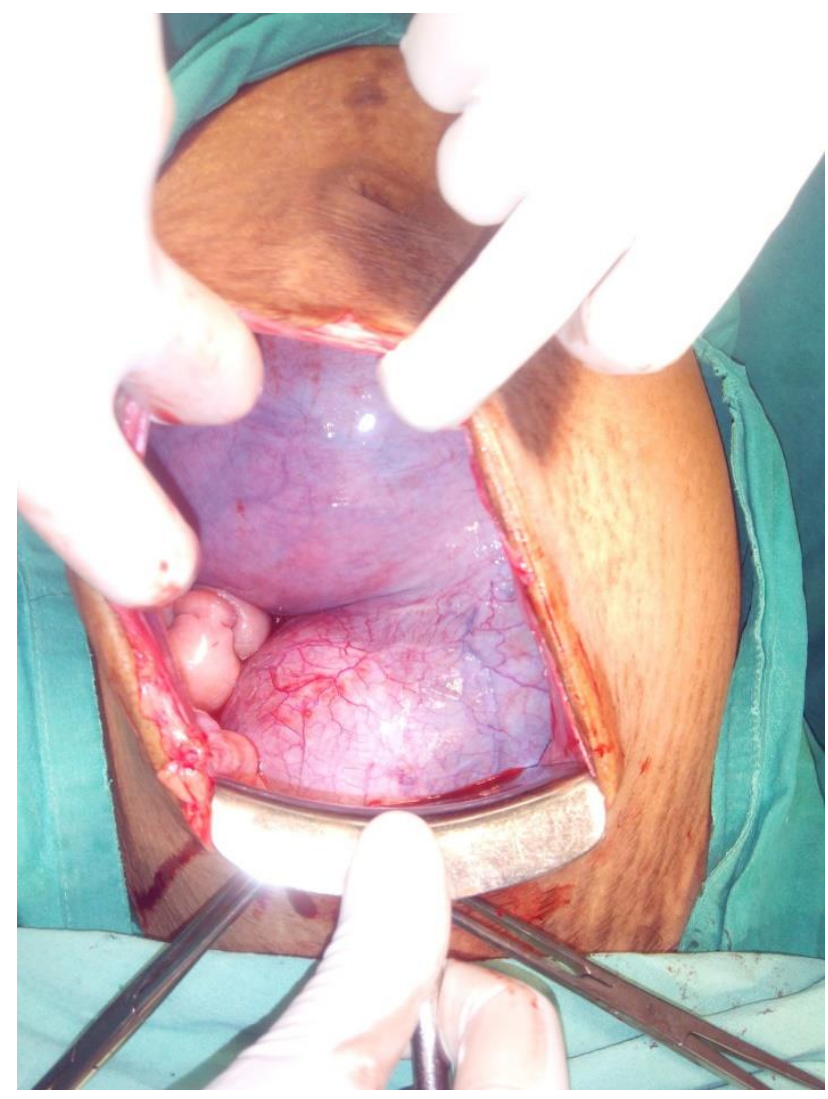

Figure 3: During surgery lower uterine segment was thickened and contraction ring of the uterine myometrium strangling the fetal head and face.

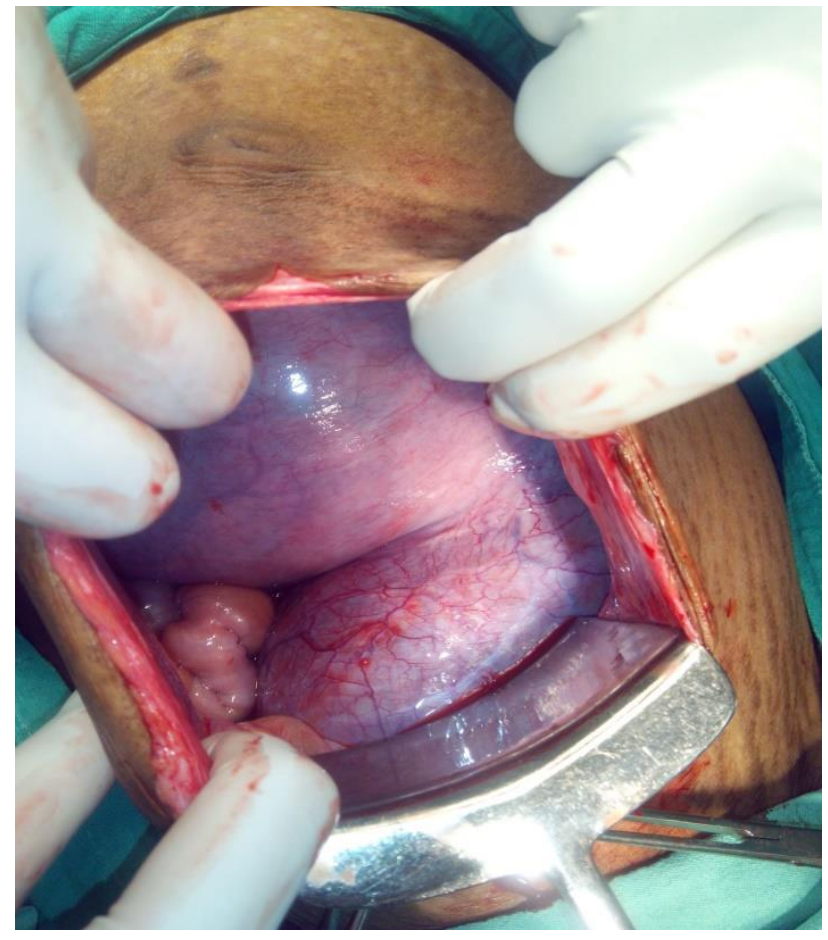

Figure 4: During LSCS lower uterine segment was thickened and contraction ring of the uterine myometrium present.

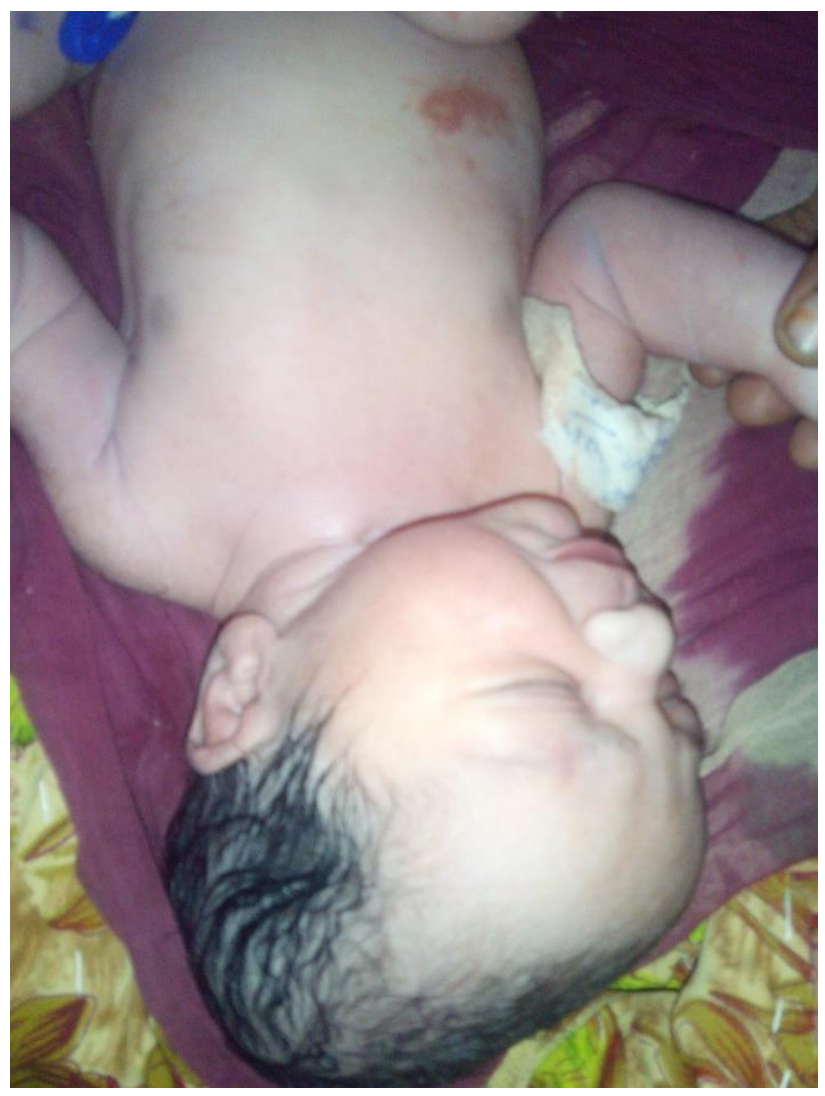

Figure 5: Mark on new-born on forehead due to ring. 


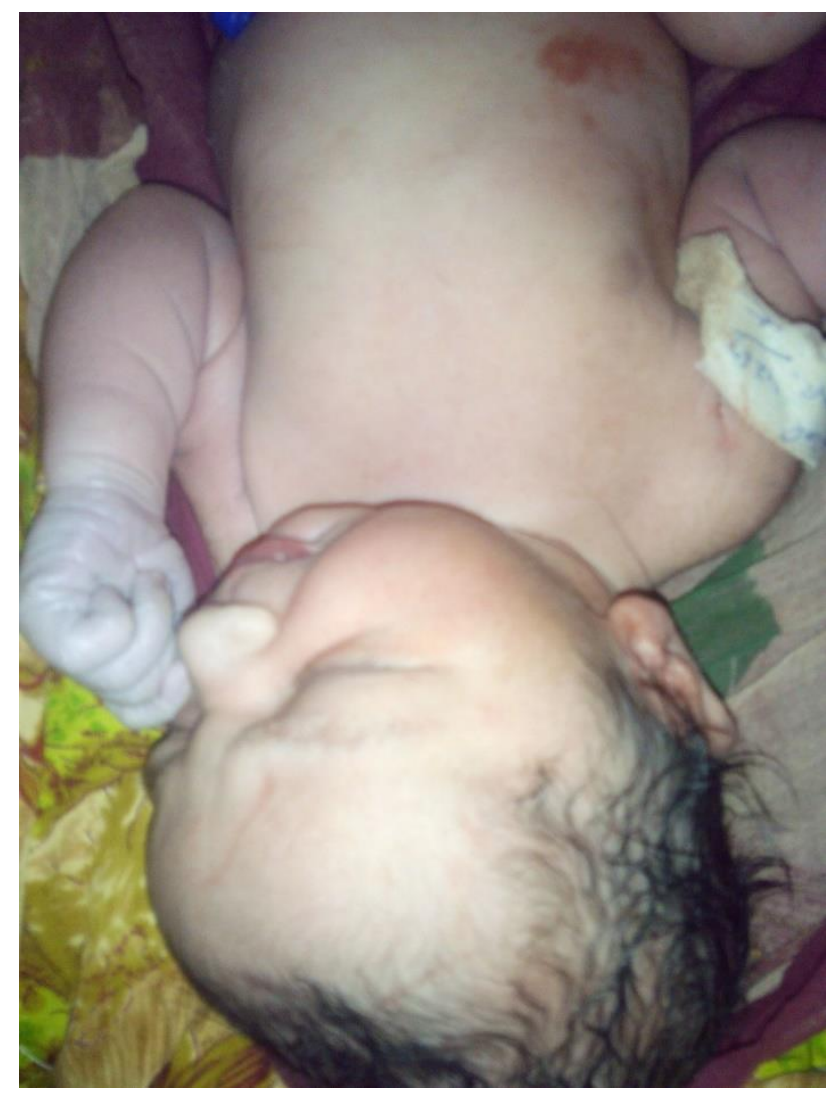

Figure 6: Mark on new-born due to ring.

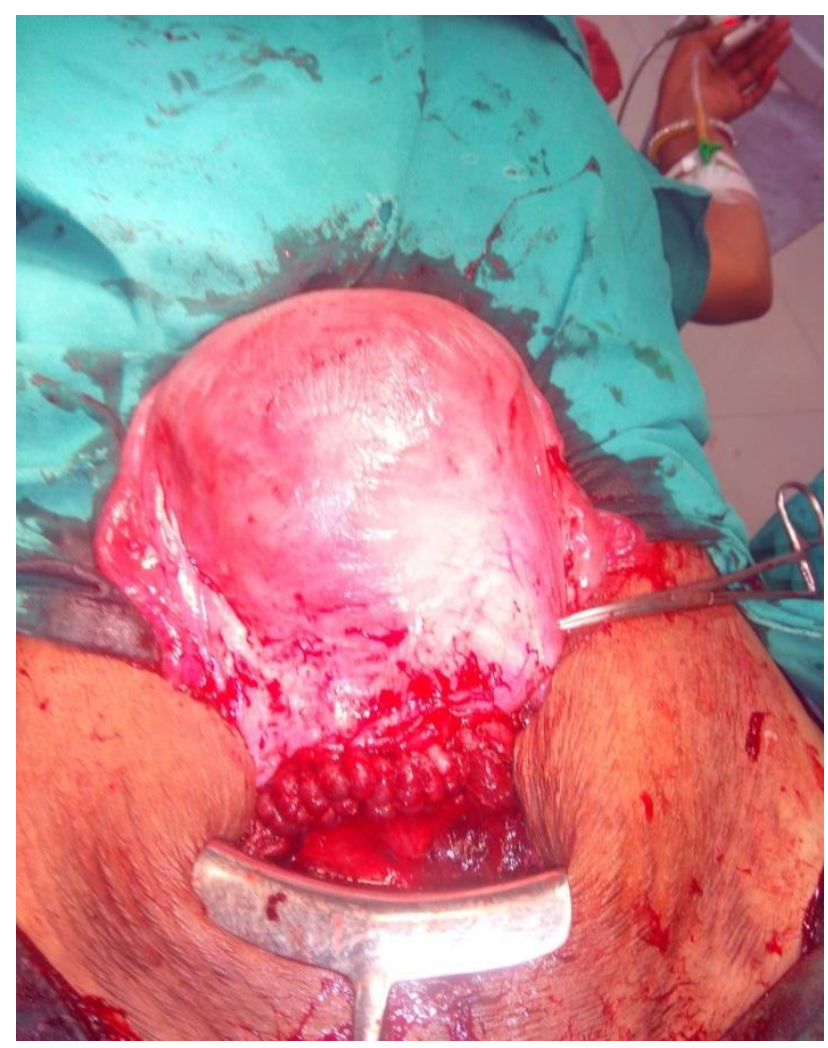

Figure 7: After closure of uterine incision uterus became normal in shape.

\section{DISCUSSION}

The occurrence of constriction ring will be one of the causes of maternal near miss and unexpected obstructed labour. Constriction ring dystocia as an incoordination of uterine activity which, by forming a circular band applied to an indentation in the contour of fetus may contribute to the failure to progress in labour. Frequency of constriction ring dystocia is $0.26 \%$, or 1 in 400 labors. Fields concluded that constriction ring dystocia is chiefly due to a functional disturbance of the uterine muscle, and as long as this persists the uterus cannot empty itself. ${ }^{6}$ In this condition there is no marked thinning of the lower uterine segment-indeed, the thickness of the uterine wall above and below the ring is approximately equal. Bandl's ring on the other hand, is regarded as an exaggeration of physiological retraction ring and is associated with excessive thinning of the lower uterine segment. To date, the pathogenesis of constriction ring dystocia has not been well documented. The elucidation of the pathogenesis and accurate diagnostic methods of constriction ring dystocia is needed by accumulation of the same case reports.

\section{CONCLUSION}

Constrictions ring in pregnancy though a rarer entity can be managed easily if diagnosed timely by signs, symptoms, and USG findings. So perinatal and obstetrics outcome improved.

\section{Funding: No funding sources Conflict of interest: None declared Ethical approval: Not required}

\section{REFERENCES}

1. Greenhill JP. Constriction ring dystocia. In: Greenhill JP (ed) Obstetrics. Asian ed.13 ${ }^{\text {th }}$ ed. Igaku Shoin Ltd, To-kyo and Osaka; 1965:838-839.

2. Jeanty P, Johns R, Boehm F. Uetrine ring and fetal demise. J Ultrasound Med. 1989;8(11):635-8.

3. Kaya $\mathrm{CH}$. Constriction ring dystocia. Can Med Assoe J. 1974;110(5):535-8.

4. Buhimschi CS, Buhimschi IA, Weiner CP. Ultrasonographie observation of Bandl's contraction ring. Int J Gynaecol Obstet. 2004;86(1):35-6.

5. Tinelli A, Di Renzo GC, Malvasi A. The intrapartum ultrasonographic detection of the Bandl's ring as a marker of dystocia. Int $\mathbf{J}$ Gynaceol Obstet. Int $\mathbf{J}$ Gynaecol Obstet. 2015;131(3):310-1.

6. Hellmen LM, Parrc Hand JA. Williams obstetrics, $14^{\text {th }}$ ed. New York, Appleton; 1971:849.

Cite this article as: Bhati BS, Patidar A, Kori A, Bhati I. An unusual case of constriction ring dystocia. Int J Reprod Contracept Obstet Gynecol 2016;5:2431-3. 